\title{
A EDUCAÇÃO PERMANENTE EM SAÚdE COMO ESTRATÉGIA PEDAGÓGICA DE TRANSFORMAÇÃO DAS PRÁTICAS: POSSIBILIDADES E LIMITES
}

\author{
CONTINUING EDUCATION IN HEALTH AS A PEDAGOGICAL STRATEGY TO TRANSFORM THE \\ PRACTICE: POSSIBILITIES AND LIMITS
}

\author{
Josiane Vivian Camargo de Lima ${ }^{1}$ \\ Bárbara Turini ${ }^{2}$ \\ Brígida Gimenez Carvalho ${ }^{3}$ \\ Elisabete de Fátima Pólo Almeida Nunes ${ }^{4}$ \\ Rafaela de Lemos Lepre 5 \\ Priscila Mainardes ${ }^{6}$ \\ Luiz Cordoni Junior ${ }^{7}$
}

Resumo Para contribuir com a transformação das práticas profissionais, foi desenvolvido um curso a distância para facilitadores de Educação Permanente em Saúde, e de Londrina participaram mais de 150 profissionais. Este estudo visa analisar as contribuições desse curso, sob a ótica dos participantes. Tratase de uma pesquisa quanti-qualitativa, e a coleta dos dados se deu a partir de grupos focais e entrevista semiestruturada. As discussões do grupo focal e da entrevista foram gravadas e transcritas, e as questões fechadas processadas pelo programa Epi Info. Os resultados apontam que o curso possibilitou a instituição de espaços coletivos de reflexão das práticas e promoveu a integração das equipes. As facilidades e dificuldades referiram-se à garantia de espaço, tempo, material e apoio, porém a motivação, interesse e participação também foram destacados. Conclui-se que houve contribuição para uma prática mais humanizada e acolhedora dos profissionais de saúde, tanto da gestão como do cuidado.

Palavras-chave educação em saúde; capacitação; recursos humanos.
Abstract To contribute to transforming professional practices, we created a distance learning course for Continuing Education in Health facilitators. Upwards of 150 professionals from Londrina took part in the course. This study aims to examine the contributions of this course from the participants' perspective. This is a quantitative and qualitative survey, and data were collected from focus groups and semistructured interviews. The focus group discussions and interviews were taped and transcribed, and the closed questions processed using the Epi Info software. The results indicate that the course allowed the deployment of collective spaces for reflection on practices and drove team integration. The facilities and difficulties involved securing space, time, material and support, but motivation, interest and participation were also highlighted. It is concluded that a contribution was made to a more humane, welcoming practice among both management and care health professionals. Keywords health education; training; human resources. 


\section{A Educação Permanente em Saúde no Brasil}

A Educação Permanente em Saúde (EPS), incluindo estratégias de capacitação de trabalhadores da área de saúde em seu processo de trabalho, vem sendo discutida na América Latina desde 1985 (Haddad; Roscke; Davini, 1990).

No Brasil, o processo de implantação do Sistema Único de Saúde (SUS) e, principalmente, a adoção da estratégia da saúde da família possibilitaram o desenvolvimento de diversas experiências de capacitação dos profissionais da área da saúde. Segundo Ceccim (2005b), estas experiências se originam de três vertentes teóricas. A primeira provém de um desdobramento da educação popular ou da educação de jovens e adultos, proposta originalmente por Paulo Freire, de onde deriva a noção de aprendizagem significativa. A segunda configura-se num desdobramento do Movimento Institucionalista em Educação, caracterizada fundamentalmente pela produção de René Lourau e George Lapassade, que reconhece que a educação se efetiva com a reformulação da estrutura e do processo produtivo em si nas formas singulares de cada tempo e lugar. Dos institucionalistas provém a noção de autoanálise e autogestão. E em terceiro, a EPS configura-se no desdobramento, sem filiação, de vários movimentos de mudança na formação dos profissionais de saúde, resultando da análise das construções pedagógicas na educação em serviços de saúde, na educação continuada para o campo da saúde e na educação formal de profissionais de saúde.

A implantação do SUS se constitui em um movimento contra-hegemônico na atual conjuntura neoliberal, tanto no contexto brasileiro quanto internacional, e há reflexões teóricas importantes sobre a necessidade de que os profissionais de saúde possuam um saber que extrapole a dimensão instrumental. Esta necessidade se justifica pelas características do processo de trabalho em saúde: tem caráter relacional, acontece no encontro trabalhador-usuário (intersubjetividade), é reflexivo, dotado de incertezas e descontinuidades, onde há impossibilidade de se padronizar completamente e a priori as atividades a serem desenvolvidas (Peduzzi, 2007; Merhy, 2002). Justifica-se pela necessidade da produção de uma atenção integral à saúde. Mattos (2001) refere que a integralidade implica recusa ao reducionismo, recusa à objetivação dos sujeitos e talvez uma afirmação da abertura para o diálogo. Aponta que a integralidade deve ser um princípio orientador tanto das práticas dos profissionais de saúde, como da organização do trabalho e das políticas de saúde.

No entanto, a formação da maioria dos profissionais atuantes nos serviços do SUS ocorreu com uma visão centrada na atenção às doenças, fragmentada e excessivamente biomédica, o que dificulta o exercício da integralidade e o desenvolvimento da participação das comunidades no cuidado, como proposto pelo SUS. 
Para o enfrentamento dessas dificuldades e, com base nas experiências de capacitação já desenvolvidas, o Ministério da Saúde criou, em 2003, a Secretaria de Gestão do Trabalho e da Educação na Saúde, com objetivo de mudança tanto na formação técnica, quanto na graduação e pós-graduação. Objetivava desencadear um processo de educação permanente dos trabalhadores de saúde com vistas a uma atenção integral à população e ao fortalecimento do SUS. Em 2004 foi instituída a Política Nacional de Educação Permanente em Saúde e foram criados Polos de Educação Permanente em Saúde em todo país (Brasil, 2004; 2005).

Em 2007 foi publicada a portaria GM/MS n. ${ }^{\circ} 1.996$, que redefiniu as diretrizes e estratégias para a implementação da Política Nacional de Educação Permanente em Saúde, adequando-a às diretrizes operacionais do Pacto pela Saúde. A principal modificação no âmbito organizacional foi a criação das Comissões Permanentes de Integração Ensino-Serviço (Cies), que juntamente com os Colegiados de Gestão Regional assumiram a responsabilidade pela elaboração do Plano de Ação Regional de Educação Permanente em Saúde, bem como pelo desenvolvimento da política de EPS no espaço de cada região.

Ceccim (2005c), ao descrever o processo de construção da política de educação permanente em saúde, salienta que a educação destes profissionais passou a ser considerada pelo Ministério da Saúde como “uma ação finalística da política de saúde e não mais como atividade-meio para o desenvolvimento da qualidade do trabalho" (Ceccim, 2005c, p. 975). No mesmo documento, o autor afirma ainda que:

A Educação Permanente em Saúde constitui estratégia fundamental às transformações do trabalho no setor para que venha a ser lugar de atuação crítica, reflexiva, propositiva, compromissada e tecnicamente competente. Há necessidade, entretanto, de descentralizar e disseminar capacidade pedagógica por dentro do setor, isto é, entre seus trabalhadores; entre os gestores de ações, serviços e sistemas de saúde; entre trabalhadores e gestores com os formadores e entre trabalhadores, gestores e formadores com o controle social em saúde. Esta ação nos permitiria constituir o Sistema Único de Saúde verdadeiramente como uma redeescola (Ceccim, 2005c, p. 976).

Nesse sentido, como estratégia para o fortalecimento da EPS, o Ministério da Saúde, em parceria com a Escola Nacional de Saúde Pública, iniciou o processo de formação de facilitadores de EPS em todo o país, a partir do segundo semestre de 2004. Inicialmente, foram selecionados 320 tutores para apoiar a formação de 6.400 facilitadores. O curso de formação dos facilitadores em EPS foi formatado na modalidade de Educação a Distância (EAD), com dois encontros presenciais e duração de cinco meses (Ceccim, 2005d). 
A proposta pedagógica do referido curso utiliza-se dos pressupostos da pedagogia crítico-social dos conteúdos, que tem por objetivo contribuir para a formação da cidadania, desenvolver nos educandos condições de criticidade, o que significa conhecimento e comprometimento político. Considera que dentro de condições histórico-sociais determinadas os conteúdos a serem trabalhados têm que ser significativos (Luckesi, 1994).

\section{Desenvolvimento da EPS em Londrina}

Em 2005, a proposta da EPS foi ampliada para municípios e regiões dispostas a adotar esta política como estratégia de gestão da produção da saúde (Brasil, 2005).

No Paraná, Londrina foi um dos municípios que compreendeu o potencial da EPS como estratégia de fortalecimento dos polos e como uma ferramenta capaz de promover mudanças no processo de trabalho em saúde. Dessa forma, foi organizado um curso de formação de 180 facilitadores para diversos profissionais, tanto da rede básica como dos serviços de apoio e representantes dos níveis secundário e terciário, das instituições formadoras, dos serviços de atendimento à urgência e representantes da comunidade. Na definição de quem seriam os profissionais do serviço municipal de saúde que fariam o curso, além da representatividade, priorizaram-se profissionais que estivessem na 'ponta', e/ou que estivessem em níveis diretivos, e que principalmente tivessem representatividade junto a seus grupos de atuação. O curso iniciou-se em setembro de 2005 e foi concluído em julho de 2006.

O presente trabalho teve como objetivo analisar a política de Educação Permanente desenvolvida no serviço municipal de saúde de Londrina, sob a ótica dos facilitadores e levantar as contribuições geradas pelo curso no processo de trabalho destes trabalhadores. Integra um projeto de pesquisa maior, intitulado "Implantação e desenvolvimento da política de educação permanente em saúde no Paraná", com apoio financeiro do CNPq por meio do edital $n^{\circ} .23 / 2006$.

\section{Desenvolvimento da pesquisa}

\section{Contexto da Secretaria de Saúde de Londrina na época da coleta de dados}

O período de coleta de dados estava previsto para acontecer a partir de janeiro de 2007. No entanto, durante o ano de 2006 ocorreram duas situações de grande impacto sobre o cotidiano dos serviços prestados na Secretaria de Saúde: a mudança do secretário de Saúde no mês de junho, com sua substi- 
tuição por uma profissional médica da própria Secretaria, e um movimento grevista deflagrado em 8 de agosto, liderado pelo sindicato dos servidores municipais e que contou com grande adesão dos servidores da área da saúde. Essa greve durou aproximadamente 90 dias, finalizando sem a obtenção de nenhuma das melhorias reivindicadas pelos trabalhadores e com desconto parcelado dos dias parados dos salários dos grevistas.

Portanto, a retomada das atividades dos trabalhadores de saúde em novembro de 2006 ocorreu de forma desestruturada, em meio a um sentimento de frustração e revolta dos funcionários. Diante desses fatos, optouse por retardar o início da coleta de dados a partir do mês de abril de 2007.

\section{População de estudo e coleta dos dados}

A população da pesquisa eram os 150 servidores da Autarquia Municipal de Saúde que participaram do curso. Estes profissionais atuavam nas unidades da rede básica, nas unidades gerenciais (diretorias e gerências), maternidade municipal e serviços de apoio à rede (policlínica, laboratório, serviço de internação domiciliar e serviço de atendimento móvel de urgência). Foram excluídos os demais 30 facilitadores inseridos em outras instituições de saúde do município.

Para obtenção dos dados, utilizou-se de metodologia quanti-qualitativa e se deu de duas formas distintas: a partir de entrevista em grupo com trabalhadores e gestores selecionados (grupo focal) e por meio de entrevista semiestruturada com todos os trabalhadores que realizaram o curso de facilitadores.

O grupo focal é uma entrevista com um pequeno grupo de pessoas (de quatro a 12 pessoas), com certa homogeneidade em termos de contexto de vida, mas não de atitudes, o que garante a riqueza das discussões (Barbour, 2009). Possibilita pensar o coletivo de uma temática que é parte integrante do cotidiano das pessoas reunidas, conhecer o processo dinâmico de interação entre os participantes, observar como as controvérsias se manifestam e são resolvidas, reproduzindo os processos de interação que ocorrem no cenário de estudo, fora dos encontros grupais (Westphal et al., 1996).

Desta forma, foram realizados dois grupos focais: um com profissionais da área gerencial da Secretaria de Saúde (convite para nove profissionais), denominado grupo focal A, e outro, para os trabalhadores das unidades básicas de saúde (UBS) (12 profissionais convidados), denominado grupo focal B. Seguindo as orientações de Goldim (2000), os participantes foram identificados por códigos, a fim de assegurar o sigilo de sua identidade. A codificação dos participantes se deu conforme a ordem em que se apresentaram nos grupos, sendo que o primeiro participante do grupo focal A a se apresentar recebeu a codificação GFAl, o segundo GFA2 e assim sucessivamente. Esta mesma metodologia foi utilizada para o grupo focal B. 
Para cada grupo focal foi realizada uma sessão de discussão, a partir de um roteiro que abordava os seguintes temas: o processo de formação de facilitadores, ações de EPS implementadas e compreensão da EPS. Os grupos focais foram desenvolvidos no Centro de Ciências da Saúde da Universidade Estadual de Londrina por quatro pesquisadores, sendo uma moderadora e três observadores, com gravação e filmagem de todo o processo. A sessão do grupo focal A foi realizada em abril de 2007, e em maio do mesmo ano para o grupo focal B.

Com base nos principais aspectos levantados nos grupos focais foi montado um roteiro semiestruturado para entrevista aos 150 participantes do curso de facilitadores, contendo questões abertas e fechadas. Teve como objetivo caracterizar os entrevistados, identificar como foi sua inclusão no curso de facilitadores, seu entendimento sobre EPS, as experiências anteriores e o desenvolvimento de atividades de EPS no local de trabalho, bem como as facilidades e dificuldades em desenvolver ações de EPS naquele momento.

As entrevistas foram realizadas no período de setembro a dezembro de 2007 por estudantes do segundo e terceiro ano do curso de medicina da UEL, integrantes do grupo de pesquisa. Para processamento das questões fechadas foi utilizado o Programa Epi Info, Versão 3.5.1.

O material proveniente dos grupos focais e das questões abertas da entrevista foi analisado por meio da análise temática. Segundo Bardin (2009), “o tema é a unidade de significação que se liberta naturalmente de um texto analisado, segundo critérios relativos à teoria que serve de guia à leitura" (Bardin, 2009, p. 131).

\section{Aspectos éticos}

Esta pesquisa foi aprovada pelo Comitê de Ética em Pesquisa da UEL (parecer n. ${ }^{\circ}$ 287/06) e autorizada pela Autarquia Municipal de Saúde. Todos os integrantes dos grupos focais, bem como os que responderam as entrevistas, assinaram o termo de consentimento livre e esclarecido para participar nas atividades da pesquisa.

\section{Resultados}

Nos dois grupos focais participaram ao todo 12 pessoas. O grupo focal de profissionais do nível central da Secretaria foi composto por cinco participantes e o de nível local por sete. Participaram: enfermeiros, auxiliares de enfermagem, dentistas, auxiliares administrativos e técnicos em higiene dental.

Foram entrevistados 104 profissionais dos 150 facilitadores inicialmente identificados, sendo excluídos os profissionais que no momento da coleta 
não atuavam mais na rede municipal de serviços, os que estavam em licença, férias e os que não foram localizados durante o período da coleta.

\section{Caracterização dos participantes do curso de facilitadores}

Dos 104 trabalhadores entrevistados, 86,5\% estão na faixa etária entre 30 e 50 anos; $86,5 \%$ são do sexo feminino; $80,7 \%$ têm um tempo de atuação profissional maior que 10 anos; 91,2\% atuam na Secretaria Municipal de Saúde há mais de cinco anos, o que demonstra que a maioria faz parte do quadro permanente dos servidores; $76,9 \%$ têm ensino superior completo e, destes, 68,2\% fizeram alguma especialização. Destas especializações, $60 \%$ são referentes à área de atuação (Saúde Coletiva, Saúde da Família e Gerência de UBS) (Tabela 1).

Tabela 1

Caracterização geral dos facilitadores no município de Londrina, 2007

\begin{tabular}{lcc}
\hline Variáveis & No & $\%$ \\
\hline & & \\
Idade & 5 & 4,8 \\
20 a 29 anos & 43 & 41,3 \\
30 a 39 anos & 47 & 45,2 \\
40 a 49 anos & 9 & 8,7 \\
Mais de 50 anos & & \\
Sexo & & \\
Feminino & 90 & 86,5 \\
Masculino & 14 & 13,5 \\
Tempo de atuação profissional & & 19,2 \\
Menos de 10 anos & 20 & 41,3 \\
10 a 19 anos & 43 & 37,5 \\
20 a 29 anos & 39 & 1,9 \\
Mais de 30 anos & 2 & 37,6 \\
& & 8,6 \\
Tempo de atuação profissional & & \\
no Serviço Municipal de Saúde & 39 & \\
Menos de 5 anos & & \\
5 a 9 anos & & \\
10 a 14 anos & 91 & \\
Mais de 15 anos & & \\
\hline
\end{tabular}


Continuação - Tabela 1

\begin{tabular}{lcc}
\hline Caracterização geral dos facilitadores no município de Londrina, 2007 & \\
\hline Variáveis & No & \\
\hline & & \\
Escolaridade & & \\
Ensino médio completo & 20 & 19,2 \\
Ensino superior incompleto & 4 & 3,8 \\
Ensino superior completo & 80 & 76,9 \\
& & \\
Especialização & & 32,4 \\
Saúde Coletiva & 23 & 25,4 \\
Saúde da Família & 18 & 2,8 \\
Gerência de UBS & 2 & 1,4 \\
Profae & 1 & 23,9 \\
Outro & 17 & 14,1 \\
Não informado & 10 & \\
Forma de inclusão no curso & & 13,5 \\
Solicitou vaga & 14 & 63,5 \\
Indicado pelo coordenador/gerente & 66 & 13,5 \\
Indicado pela equipe & 14 & \\
Outra forma & & \\
\hline
\end{tabular}

Fonte: Os autores.

Dentre os concluintes, 63,5\% referiram não ter tido experiência anterior em EPS. Este resultado nos leva a refletir que alguns processos de EPS, que foram desenvolvidos anteriormente pelo serviço, não foram reconhecidos como tal pelos trabalhadores, como as oficinas para discussão do processo de trabalho e de planejamento local pelas equipes. A partir disso nos questionamos: será que a concepção de EPS dos entrevistados é somente aquela que se constitui formalmente enquanto curso?

A inclusão dos participantes no curso foi por indicação da coordenação/gerência $(63,5 \%), 13,5 \%$ foram indicados pela equipe, podendo-se inferir, com isso, o papel de liderança do profissional junto a seus colegas de trabalho.

Em relação às funções exercidas pelos facilitadores detectou-se 11 diferentes funções exercidas pelos entrevistados (Tabela 2). 
Tabela 2

\begin{tabular}{lcc}
\hline Funções desempenhadas pelos facilitadores do Serviço Municipal de Londrina, entrevistados em 2007 \\
\hline Função que desempenha no Serviço Municipal de Saúde & $\mathbf{N}^{\circ}$ & $\%$ \\
\hline & & \\
Auxiliar de clínica odontológica & 1 & 1,0 \\
Agente comunitário de saúde & 4 & 3,8 \\
Auxiliar de enfermagem & 1 & 23,0 \\
Cargo comissionado & 8 & 1,0 \\
Dentista & 46 & 7,7 \\
Enfermeira & 1 & 44,2 \\
Farmacêutica & 11 & 1,0 \\
Médico & 1 & 10,6 \\
Psicólogo & 4 & 1,0 \\
Técnico administrativo & 3 & 3,8 \\
Técnico em higiene dental & & 2,9 \\
Total & 104 & 100,0
\end{tabular}

Fonte: Os autores.

Dentre as funções, 44,2\% eram enfermeiras; $23 \%$, auxiliares de enfermagem; e 10,6\%, médicos. Outro dado importante foi que durante o curso apenas dois médicos e 37 enfermeiras exerciam algum cargo de gestão/gerência, e no momento da pesquisa, nove e 39, respectivamente, o exerciam. Este resultado nos sugere que o curso pode ter propiciado a aquisição de ferramentas que subsidiaram a formação para a gestão.

Dos 34,6\% de facilitadores que exerciam função de nível médio, observou-se que somente $23 \%$ referiram não ter curso superior completo, indicando que vários profissionais que atuam em funções técnicas possuem formação de terceiro grau.

Participaram do curso profissionais de diferentes funções, inseridos em diversos setores da rede municipal de saúde, tanto de unidades de atenção ao usuário quanto de unidades de apoio à rede. Esta participação propiciou a integração e compreensão do trabalho dos envolvidos nos diferentes pontos da rede de atenção, o que foi destacado como positivo, pois proporcionou sentimento de inclusão. 
(...) eu trabalho com recursos humanos, com pessoal. (...) como é um serviço de apoio, era assim, um serviço fora da saúde. Os trabalhadores não se sentiam valorizados, (...) Então, pra entender melhor esse processo, o curso de facilitadores ajudou bastante. Deu pra entender (...) o papel dos nossos trabalhadores, da nossa clientela onde a gente trabalha. Então eu acho que abriu a cabeça de muita gente (GFAl).

O trabalho em saúde envolve a participação de diferentes profissionais que devem atuar de forma complementar. Contudo, esta integração que deveria se concretizar no dia-a-dia do trabalho não acontece por diversas razões, sobretudo pela fragmentação da assistência e pelo distanciamento dos setores que exercem atividades meio e fim na rede de atenção. Com a “valorização da técnica e da fragmentação ocorre distanciamento do usuário e perda da dimensão deste, como sujeito no processo de saúde" (Abrahão e Cassal, 2009, p. 256).

Morin (2006) critica a sociedade ao afirmar que esta se empenha em fragmentar a realidade, a qual é multidimensional e complexa. Diante de um contexto que privilegia a fragmentação, é importante perceber que o curso de facilitadores trouxe contribuições no sentido de estimular os profissionais do nível central a desenvolverem a contextualização e interação dos fenômenos que acontecem na 'ponta' do serviço.

\section{A EPS como instituidora de espaços coletivos de reflexão das práticas}

A EPS desenvolvida na Secretaria Municipal de Saúde foi entendida como estímulo para mudanças no processo de trabalho nas equipes, para uma melhor adequação dos atendimentos prestados ao modelo de atenção integral à saúde, como é proposto pelo SUS.

A educação permanente ela é realmente um instrumento de construção, que além do sentido da roda que se faz, no sentido horizontal [em] que as pessoas estão, é possível construir (...) (GFB6).

(...) era muito legal ver os agentes comunitários, os auxiliares de enfermagem discutindo: 'O princípio do SUS, a integralidade. (...) e a equidade (...) ver (...) toda uma unidade discutindo esses conceitos foi o maior ganho que o curso de facilitadores propiciou pra mim (GFA3).

A partir das falas, observamos que este processo de EPS propiciou a construção de espaços mais democráticos de discussões, permitindo o aprendizado coletivo e discussão de conceitos importantes para a direcio- 
nalidade do cuidado. Além disso, disparou a transformação dos processos, tanto da gestão quanto do cuidado.

A problematização das práticas utilizadas no curso de facilitadores permitiu uma melhor integração não só dos profissionais das equipes de saúde, mas também interequipes e interníveis, tornando as reuniões nas UBS menos informativas e mais participativas. Estimulou o desenvolvimento de processos de planejamento ascendente e a responsabilização dos membros das equipes de saúde pela execução das atividades propostas.

A gente começou a tomar decisões de uma forma mais ascendente, (...) a construir isso junto com todos, seja a pessoa que fosse, independente do papel que ela tinha no momento.(...) As pessoas pararam para planejar, que era uma coisa que não existia na nossa prática, isso foi um ganho muito grande (...) as pessoas começaram a se sentir responsáveis pela ação (GFA5).

Antigamente, antes do curso, a gente já predeterminava: 'vai mudar tal coisa, vai ser assim'. A gente só passava o que ia acontecer. (...) Mas [hoje é] assim: 'o que vocês pensam de tal coisa, que nós estamos pensando que não está bom? (...) O que a gente poderia fazer pra mudar? Então isso mudou com o curso (GFB3).

Este processo reflexivo estimulou a participação dos trabalhadores, facilitando a sua inclusão nas equipes de trabalho, com intervenção e mudança nas práticas, atingindo o principal objetivo da EPS, como é apontado pela fala abaixo:

Nós tivemos também (...) alguns momentos de problematização. Então a equipe conseguiu fazer a problematização das rotinas de trabalho e até de algumas questões estruturais, físicas, de recursos humanos, de papel e a gente teve alguns ganhos com isso (GFA5).

Estes apontamentos dos grupos focais foram referendados pelos resultados relacionados às atividades desenvolvidas pelos facilitadores após o término do curso. As mais referidas foram as atividades em grupo com a equipe, reuniões, discussão de casos/problemas $(90,7 \%)$ e atividades educativas com a comunidade/grupos (49,3\%).

A reflexão sobre as práticas pode ser constatada nas entrevistas, em que $72 \%$ dos trabalhadores afirmaram que continuavam a desenvolver atividades de EPS no cotidiano de seu trabalho após o término do curso.

Bagnato e Monteiro (2006) apontam que

pensar outras formas de atenção à saúde para a população implica, entre outras atitudes, rever as relações de trabalho no setor, as características dos profissionais 
que estão sendo formados, remetendo-nos aos pressupostos que têm respaldado suas formações e práticas (Bagnato e Monteiro, 2006, p. 250).

Relacionam a realização de práticas fragmentadas, isto é, olhar o sujeito (seu 'objeto') dividindo-o em partes numa ótica especializada com pouco espaço para criação ao predomínio da formação disciplinar que decompõe um campo de conhecimento, não estabelecendo e dificultando a comunicação, a recontextualização e as interconexões desses saberes com outros em sua complexidade (Bagnato e Monteiro, 2006, p. 250).

No sentido de superar esta realidade da prática dos profissionais já inseridos no serviço, é necessário compreender a EPS como proposta pedagógica que desenvolve seu processo educativo no cotidiano do trabalho em saúde, colocando este trabalho em análise. Esta estratégia pedagógica é atravessada pelas relações concretas que operam realidades e possibilita construir espaços coletivos para a reflexão e avaliação de sentido dos atos produzidos no cotidiano (Ceccim, 2005b). Isto deve ser visto na perspectiva de que a ação produtiva é duplamente transformadora, em que ao mesmo tempo em que o trabalhador produz os atos de cuidado, mudando a realidade, produz a si mesmo como sujeito (Franco, 2007).

Enquanto prática pedagógica deve contemplar os mais recentes aportes teóricos, metodológicos, científicos e tecnológicos disponíveis, ao mesmo tempo em que se faz necessária a construção de relações e processos que vão do interior das equipes em atuação conjunta, passando às práticas organizacionais e às práticas interinstitucionais e/ou intersetoriais, implicando os agentes, as instituições de saúde e as políticas nas quais se inscrevem os atos de saúde (Ceccim, 2005a).

Como apresentado por este autor,

a construção conceitual e prática do trabalho em equipe decorre do esforço de mudar o trabalho técnico verticalmente hierarquizado para um trabalho com interação social entre os trabalhadores, com possibilidades à autonomia e à criatividade no fazer coletivo (Ceccim, 2005a, p. 168-169).

Por considerar a existência de um espaço de autogoverno dos trabalhadores da saúde e a insuficiência dos processos normativos de controle utilizados pelas organizações para a instituição de novas práticas, a aposta tem sido desencadear dispositivos que possibilitem aos trabalhadores a reflexão e a problematização de suas práticas, isto é, pensar sobre determinadas situações e questioná-las de modo a compreender a maneira como os processos são desencadeados.

Para Merhy, Feuerwerker e Ceccim (2006), o ato de problematizar a realidade gera o desejo de mudança, uma vez que favorece a sensação de incô- 
modo, a percepção de insatisfação com o realizado. Para estes autores, o incômodo só é percebido quando vivido de forma intensa, ou seja, por meio da vivência e da reflexão sobre as práticas cotidianas.

A política de EPS proposta pelo Ministério da Saúde reforça a importância da problematização ao afirmar que a reflexão sobre a qualidade da atenção individual, coletiva e sobre a organização do sistema de saúde tem a possibilidade de reorganizar os processos formativos, transformando as práticas educativas e de assistência à saúde. A experiência da problematização favorece o desenvolvimento de escutas, de práticas cuidadoras em que o sujeito é o centro e visto de forma integral (Ceccim, 2005c,d).

\section{A EPS: indutora da integração da equipe}

Em relação às mudanças desencadeadas pela EPS, 70,2\% dos participantes referiram acreditar que o processo produziu algum tipo de mudança no modelo de atenção do município, sendo que destes $44,2 \%$ disseram que as mudanças foram parciais.

Dentre as mudanças, foram citadas: ampliação do vínculo entre os profissionais da equipe (84,9\%), aumento do acolhimento e humanização $(83,6 \%)$, maior democratização da gestão $(77,3 \%)$ e ampliação do conhecimento das necessidades de saúde da comunidade $(60,3 \%)$.

Embora o controle social seja um dos preceitos do SUS e objeto de investimento do processo de EPS, o desenvolvimento do controle social não foi percebido como mudança por $82,2 \%$ dos profissionais, pois somente $24 \%$ dos concluintes referiram estar desenvolvendo atividades com os conselhos locais de saúde após o término do curso.

Quanto à utilização do sistema de informação como ferramenta para a mudança no modelo de atenção, apenas 39,7\% referiram que houve maior apropriação das informações disponibilizadas pelos sistemas. Em relação à ampliação do vínculo entre os profissionais atuantes nas equipes multiprofissionais, os participantes dos grupos focais destacaram a integração do setor de odontologia que tradicionalmente trabalhava de forma mais isolada dos outros setores das UBS.

Eu me lembro que quando entrei no serviço eu tinha uma visão: eu era uma dentista, eu cuidava da boca e minha função era aquela. Hoje, a partir da educação permanente, (...) você vai vendo o indivíduo mais como um todo. Por exemplo: a pediatria pede para eu dar uma olhada em alguma coisa, às vezes eu peço para ela me auxiliar. Então nós estamos tentando já articular em alguma coisa que é interdisciplinar (GFB6). 
Além dos dentistas, muitos profissionais médicos apresentavam grande dificuldade de integração com os demais membros da equipe.

(...) médico não sentava numa mesa de café com auxiliar de enfermagem ou com uma enfermeira. Pra vocês verem como era a diferença. Com essas reuniões, eles já sentavam nas mesmas mesas e já discutiam. (...) (GFA2).

Esta dificuldade de integração e do desenvolvimento do trabalho em equipe é resultado de como se estruturou o processo de trabalho na área da saúde. Nesta área, o processo de trabalho tem natureza coletiva, onde vários profissionais procuram agir coerentemente, compartilhando conhecimentos e ações. No entanto, no cotidiano do trabalho, estes agentes desenvolvem processos de trabalho próprios, parcelares e são valorizados diferentemente segundo os vários fazeres, com destaque para a nucleação que o profissional médico ocupa neste processo. É condicionado pelo estágio de conhecimento e percepção das necessidades, que se dá de acordo com as concepções e valores morais, éticos e ideológicos dos profissionais, pois envolve interpretação e decisão pessoal na aplicação do conhecimento científico (Nogueira, 1995; Pires, 1998).

Almeida e Mishima (2001) apontam que um dos grandes desafios está na constituição de equipes de saúde para além de um trabalho técnico hierarquizado, com interação social entre os trabalhadores, com maior horizontalidade e flexibilidade dos diferentes poderes, possibilitando maior autonomia e criatividade dos agentes e maior integração da equipe.

Na discussão sobre o trabalho em equipe nos grupos focais, inicialmente este era entendido apenas como a justaposição de diversas categorias profissionais, com a realização das diferentes tarefas de forma paralela, em que cada um cuidava apenas de suas atribuições, sem ter uma visão clara do trabalho conjunto da UBS. E que, a partir do processo de EPS, houve a mudança de postura de vários profissionais, no sentido de uma relação mais efetiva, um real processo de integração.

Então, hoje eu acho que a integração é que eu tenha a preocupação do que está acontecendo na recepção, o número de consultas que está sendo pouco, os conflitos entre os auxiliares de enfermagem. Tudo isso me interessa e tudo se reflete ali dentro e sabe que está interferindo também. A partir deste momento, os problemas do posto passaram a ser meus problemas também (GFB6).

A integração da equipe foi entendida como um conjunto articulado de ações com vistas à melhoria do serviço de saúde, estando mais próxima do conceito de equipe integração, caracterizada pela articulação das ações a partir da interação dos agentes (Peduzzi, 2001). Segundo esta autora, a inte- 
ração é expressa pela forma de comunicação entre os membros da equipe, que pode ser apenas como instrumento técnico, ou de caráter pessoal, indicando amizade ou camaradagem entre os agentes. No entanto, nessa forma de comunicação não há um 'agir comunicativo', que se caracteriza, de acordo com Peduzzi, principalmente pela construção de um projeto assistencial comum.

\section{Situações que potencializam a EPS}

Dos entrevistados, 49,1\% disseram encontrar facilidades para implementar a EPS no seu local de trabalho, enquanto que $86,6 \%$ referiram alguma dificuldade neste processo.

Chama atenção o fato de que uma mesma condição foi referida por alguns como dificuldade e por outros como facilidade para o desenvolvimento da EPS. A categorização das facilidades e dificuldades abaixo apontadas, como pares de opostos, pode ser indicativa da heterogeneidade dos contextos e dos sujeitos envolvidos nos diversos locais de trabalho do serviço municipal de saúde. As condições apontadas pelos entrevistados estão relacionadas às áreas em que a EPS se propõe a intervir: práticas profissionais/relação no trabalho, gestão setorial e controle social (Quadro 1).

Categorização das condições referidas pelos trabalhadores da Secretaria Municipal de Saúde como facilidades e dificuldades para a implementação da EPS, Londrina, 2007

$\begin{array}{ll}\text { Facilidades Dificuldades } & \end{array}$

Relacionadas às práticas profissionais e relações no trabalho

Adesão da equipe à proposta de EPS, equipe interessada, capacitada, aberta a mudanças.

Melhor utilização dos dados e informações de saúde disponíveis para realizar o planejamento do trabalho.

Compreensão e utilização dos conteúdos de EPS/reorganização do processo de trabalho.

Disponibilidade de tempo para realizar atividades.
Resistência da equipe às mudanças, falta de interesse, dificuldade de sensibilização e desmotivação dos profissionais, descrédito no processo de EPS.

Dificuldade de pôr em prática os conceitos de EPS; falta de instrumentos de planejamento e falta de governabilidade.

Falta de compreensão de EPS e sua importância. Falta de compreensão do SUS.

Alta demanda, sobrecarga de trabalho, falta de recursos humanos, saída e ou transferência de funcionários. 
Categorização das condições referidas pelos trabalhadores da Secretaria Municipal de Saúde como facilidades e dificuldades para a implementação da EPS, Londrina, 2007

\begin{tabular}{ll}
\hline Facilidades & Dificuldades \\
\hline
\end{tabular}

Relacionadas à gestão

Apoio da Autarquia de Saúde, dos gestores e dos coordenadores; realização de oficinas com a coordenação; planejamento, apoio e autonomia para fechar UBS para reuniões de equipe, disponibilidade de material.

Democratização da gestão (reuniões participativas) e resolução de problemas /democratização do espaço.
Ambiente político desfavorável/questões salariais, greve, resistência por oposição política.

Descontinuidade do processo.

Relacionadas ao controle social

\begin{abstract}
Adesão/compreensão das lideranças locais,
Falta de contato com a comunidade/inexistência de acolhimento da comunidade.

conselho atuante.
\end{abstract}

Fonte: Os autores

Esta ambiguidade sinalizada na figura acima pode nos indicar que esta proposta de curso de educação permanente, mesmo tendo o propósito de se institucionalizar, não foi assumida como política de saúde pelos profissionais do serviço, o que a cada mudança de gestão representa um recomeçar. Esta descontinuidade faz com que os serviços estejam sempre reiniciando, e os profissionais dos serviços de saúde colocando-se em uma posição de espectadores e não de agentes proativos, desmotivando-se a quaisquer elementos que caracterizem descontinuidade (questões salariais, sobrecarga de trabalho, alta demanda, entre outros) e que nada mais são do que as formas históricas de construir o continuísmo, pois não permite a ruptura, essencial aos processos de transformação (Collares, Moyses, Geraldi, 1999).

Em relação às práticas profissionais, foi referido nos grupos focais que, embora compreendessem o curso de facilitadores como instrumento para mudanças, os costumes e práticas cristalizadas dificultaram a adesão ao processo.

Na minha opinião, com relação à parte cultural, [há] uma história de vida desde lá de trás, que vem daquele modelo sustentado no médico, na medicalização. (...) Então, é mais difícil você conseguir que melhore a qualidade (GFB3). 
Por que as coisas, elas estão do jeito como que elas estão? Na minha opinião (...) é porque as pessoas querem em sua maioria que elas estejam da maneira como elas estão. Os pacientes, principalmente a população de um modo geral, e os funcionários, (...). Então ao mexer com isso daí, você está indo contra uma situação preestabelecida, não é fácil (GFB6).

Contudo, a heterogeneidade das equipes pode se constituir como elemento capaz de potencializar transformações nos processos de trabalho.

A equipe era muito heterogênea. Você tem desde profissionais que há quase 30 anos estão ali, como tem gente chegando (...). Então, as experiências são as mais diversas possíveis (GFBl).

(...) é possível construir com essa diversidade que a gente já colocou. São diversos olhares que favorecem isso. Lógico que é uma arena de discussão. Uma arena de novas ideias (GFB5).

A constituição das práticas profissionais é tema de estudo de vários autores (Cecilio, 2007; Merhy, 2002). Merhy (2002) defende a ideia de que todos os atores na saúde são, em alguns momentos, instituintes de novas práticas e, em outros, reprodutores de processos instituídos.

Parto do princípio que somos, em certas situações, a partir de certos recortes, sujeitos de saberes e das ações que nos permitem agir protagonizando processos novos como força de mudança de mudanças. Mas, ao mesmo tempo, sob outros recortes e sentido, somos reprodutores de situações dadas. Ou melhor, mesmo protagonizando certas mudanças, muito conservamos (Merhy, 2002, p. 14-15).

Para os sujeitos da pesquisa, a adesão ao processo de EPS não foi uniforme entre as equipes. Foram mencionados como possíveis fatores para este fenômeno conflitos político-partidários, insatisfação ou desmotivação geral dos trabalhadores, pressão da demanda cotidiana, dúvida sobre a sintonização com outros níveis de gestão da saúde, entre outros.

(...) relacionavam a questão do curso com política partidária. 'Isso aí é do partido', (...) então muitos não receberam; não teve muito apoio. Teve unidade que caminhou bem, (...) Teve unidade que não caminhou (GFA4).

Muitas vezes o profissional também está desinteressado. O que isso vai mudar pra mim? O que eu vou ganhar com isso? Vou carregar demais esse trabalho que gera conhecimento, que gera trabalho, que você tem que parar, que você tem que se responsabilizar pelas decisões tomadas nas reuniões que acontecem na UBS, e 
muitas vezes ele acaba por ficar quieto: 'Melhor eu ficar quieto, não assumir essa responsabilidade', e às vezes até pagar com responsabilidades dos outros (GFB4).

A gente sabe que o nosso trabalhador tem essa visão, que tem que atender o usuário. A assistência do usuário, centrar no usuário e não nas pessoas que fazem a assistência. Só que o dia-a-dia é muito cruel. A gente lida com pessoas e conflitos a todo o momento. É conflito, são insumos que a gente tem que gerenciar. Então a gente às vezes acaba dando prioridade a essas coisas e deixando de ajudar (GFA4).

A maneira como cada sujeito reage às propostas de mudança está relacionada aos modos e processos de subjetivação. De acordo com Ramminger e Nardi (2008), os modos de subjetivação de uma categoria de trabalhadores referem-se

(...) ao modo predominante e a como os trabalhadores relacionam-se com o regime de verdades que atravessa seu trabalho (os discursos da qualidade total, da eficiência, do 'vestir a camiseta'), vendo-se ligados ao cumprimento de determinadas regras estabelecidas por esse discurso que, ao mesmo tempo, permitem seu reconhecimento enquanto trabalhador. Já o processo de subjetivação seria como cada trabalhador vivencia essa relação em sua trajetória particular (Ramminger e Nardi, 2008, p. 342).

As respostas aos processos disparados pelos gestores nem sempre atingem a dimensão esperada, tendo em vista que os atores na saúde disputam seus projetos individuais de cuidado e de gestão (Merhy, 2002). Cecilio (2007) reforça esta ideia, afirmando que

Os trabalhadores dançam (...) mas nem sempre conforme a música que a direção toca. São instituintes, o tempo todo, de novas institucionalidades que não são, necessariamente, as portadas pelos conceitos que estamos tentando traduzir em novas práticas (Cecílio, 2007, p. 347).

\section{Considerações finais}

Apesar de todas as dificuldades existentes num processo de EPS, é inegável que o trabalho desenvolvido em Londrina foi um processo que permitiu avanços no sentido de uma prática humanizada e acolhedora dos profissionais de saúde, tanto na dimensão da gestão como do cuidado. Possibilitou espaços de participação dos profissionais envolvidos e melhor compreensão das atividades desenvolvidas na atenção básica pelos funcionários de outros 
setores, o que facilitou certa horizontalização da relação entre as diversas unidades e serviços.

A diversidade da realidade das unidades refletiu-se nas respostas heterogêneas ao processo da EPS, em que situações foram consideradas dificultadoras para uns e facilitadoras para outros. Apesar de os trabalhadores das unidades estarem submetidos às mesmas regras, normalizações de serviços, e condições físico-estruturais, estes apresentam diferentes percepções relativas às potencialidades representadas pelas condições de desenvolvimento de uma proposta de EPS. Isto se deve ao fato das concepções e das práticas profissionais serem dependentes do processo de subjetivação de cada trabalhador; ou seja, a maneira como cada trabalhador, em sua trajetória particular, vivencia a relação com as regras, ou como se identifica com o regime de verdades que atravessa seu trabalho.

No entanto, é importante oportunizar a reflexão sobre o processo de trabalho em saúde, seja no trabalho, ou em outros espaços de discussão. Por meio do processo de EPS, embora tenha havido solução de continuidade, muitos dos sujeitos tiveram a possibilidade de olhar para a própria prática de trabalho, ampliaram a capacidade de análise e tornaram-se aliados na construção de um projeto social e de saúde que atende aos preceitos da nossa Carta Magna: 'saúde: direito de todos e dever do Estado'.

\section{Notas}

1 Professora da Universidade Estadual de Londrina, Londrina, Paraná, Brasil. Mestrado em Saúde Coletiva pela Universidade Estadual de Londrina. <josivivian@gmail.com> Correspondência: Rua Amador Bueno, 367, apto. 101, CEP 86010-620, Vila Ipiranga, Londrina, Paraná, Brasil.

2 Professora assistente da Universidade Estadual de Londrina, Londrina, Paraná, Brasil. Mestrado em Saúde Coletiva pela Universidade Estadual de Londrina. <turini@ sercomtel.com.br>

3 Professora assistente do Departamento de Saúde Coletiva da Universidade Estadual de Londrina, Londrina, Paraná, Brasil. Doutoranda pela Escola de Enfermagem da Universidade de São Paulo. <brigidagimenez@gmail.com>

4 Professora adjunta da Universidade Estadual de Londrina, Londrina, Paraná, Brasil. Doutorado em Saúde Coletiva pela Universidade Estadual de Campinas. $<$ alnunes@sercomtel.com.br> 
5 Graduanda de Medicina da Universidade Estadual de Londrina, Londrina, Paraná, Brasil. <rafa_lepre@yahoo.com.br>

6 Graduanda de Medicina da Universidade Estadual de Londrina, Londrina, Paraná, Brasil.<prismainardes@yahoo.com.br>

7 Professor da Universidade Estadual de Londrina, Londrina, Paraná, Brasil. Doutorado em Saúde Pública pela Universidade de São Paulo. <cordoni@sercomtel.com.br>

\section{Referências}

ABRAHÃO, Ana Lucia; CASSAL, Luan Carpes Barros. Caminhos para a integralidade na educação profissional técnica de nível médio em saúde. Trabalho, Educação e Saúde, Rio de Janeiro, v. 7, n. 2, p. 249-264, 2009.

ALMEIDA, Maria Cecília Puntel.; MISHIMA, Silvana Martins. O desafio do trabalho em equipe na atenção à Saúde da Família: construindo 'novas autonomias' no trabalho. Interface - Comunicação, Saúde, Educação, Botucatu, v. 5, n. 9, p. 150-153, 2001.

ASCHIDAMINI, Ione Maria; SAUPE, Rosita. Grupo focal, estratégia metodológica qualitativa: um ensaio teórico. Cogitare Enfermagem, v. 9, n. 1, p. 9-14, 2004.

BARBOUR, Rosaline. Grupos focais. Tradução de Marcelo Figueiredo Duarte. Porto Alegre: Artmed, 2009.

BAGNATO, Maria Helena Salgado; MONTEIRO, Maria Inês. Perspectivas interdisciplinar e rizomática na formação dos profissionais da saúde. Trabalho, Educação e Saúde, Rio de Janeiro, v. 4 n. 2, p. 247-258, 2006.

BARDIN, Laurence. Análise de conteúdo. Lisboa: Edições 70, 2009.

BRASIL. A Educação Permanente entra na roda: polos de educação permanente em saúde. Conceitos e caminhos a percorrer. Brasília, DF: Ministério da Saúde, 2005. 36 p.
. Ministério da Saúde. Secretaria de Gestão do Trabalho na Saúde. Departamento de Gestão da Educação na Saúde. Política de educação e desenvolvimento para o SUS: caminhos para a educação permanente em saúde. Polos de educação permanente em saúde. Brasília, DF: Ministério da Saúde, 2004. 68p.

Ministério da Saúde. Gabinete do Ministro. Portaria GM/MS n. ${ }^{\circ} 1.996$, de 20 de agosto de 2007. Dispõe sobre as diretrizes para a implementação da Política Nacional de Educação Permanente em Saúde e dá outras providências. Brasília, DF: MS, agosto de 2007.

CECCIM, Ricardo Burg. Onde se lê 'recursos humanos da saúde', leia-se 'coletivos organizados de produção da saúde': desafios para a educação. In: Pinheiro, ROSENI; MATTOS, Ruben Araújo de (Org.). Construção social da demanda: direito à saúde, trabalho em equipe, participação e espaços públicos. Rio de Janeiro: Cepes/Uerj: Abrasco, 2005a. p. 161-180.

Educação permanente em saúde: desafio ambicioso e necessário. Interface Comunicação, Saúde, Educação, Botucatu, v. 9, n. 16, p. 161-177, 2005 b.

Educação Permanente em Saúde: descentralização e disseminação de capacidade pedagógica na saúde. Ciência \& Saúde Coletiva, Rio de Janeiro, v. 10, n. 4, p. 975986, 2005c. 
Prefácio. In: BRASIL. Ministério da Saúde. Secretaria de Gestão do Trabalho e da Educação na Saúde. Departamento de Gestão da Educação na Saúde. Curso de formação de facilitadores em Educação Permanente em Saúde: orientação para o curso. Rio de Janeiro: MS/Fiocruz, 2005d. p. 11-12.

CECÍlLIO, Luiz Carlos Oliveira. O 'trabalhador moral' na saúde: reflexões sobre um conceito. Interface - Comunicação, Saúde, Educação, Botucatu, v. 11, n. 22, p. 345-63, maio/ago. 2007.

COLLARES, Cecília Azevedo Lima; MOYSES, Maria Aparecida Afonso; GERALDI, J.W. Educação continuada: a política da descontinuidade. Educação \& Sociedade [online], vol. 20, n. 68, p. 202-219, 1999.

FRANCO, Túlio Batista. Healthcare production and pedagogical output: integration of healthcare system settings in Brazil. Interface - Comunicação, Saúde, Educação, Botucatu, v. 11, n. 23, p. 427-38, set./dez. 2007.

GOLDIM, J. R. Manual de iniciação à pesquisa em saúde. Porto Alegre: Dacasa, 2000.

HADDAD, Jorge; ROSCHKE, Maria Alice Clasem.; DAVINI, Maria Cristina. Proceso de trabajo y educacion permanente de personal de salud: reorientacion y tendencias en America Latina. Educacion Médica y Salyud, Washington, v. 24, n. 2, p. 136-204, 1990.

LUCKESI, Cipriano Carlos. Filosofia da educação. São Paulo: Cortez, 1994.

MATTOS, Ruben Araujo. Os sentidos da integralidade: uma reflexão acerca dos valores que merecem ser defendidos. In: PINHEIRO, Roseni; MATTOS Rubens A. (Org.). Os sentidos da integralidade na atenção e no cuidado à saúde. Rio de Janeiro: Uerj, IMS, Abrasco, p. 39-64, 2001.

MERHY, Emerson Elias. Saúde: a cartografia do trabalho vivo. São Paulo: Hucitec, 2002.
MERHY, Emerson Elias; FEUERWEKER, Laura Camargo Macruz; CECCIM, Ricardo Burg. Educación permanente en salud uma estrategia para intervenir en la micropolítica del trabajo en salud. Salud Colectiva, Lanús, v. 2, n. 2, p. 147-60, 2006.

MORIN, Edgar. Os sete saberes necessários à educação do futuro. São Paulo: Cortez, 2006.

NOGUEIRA, Roberto Passos. O trabalho em serviços de saúde. In: Brasil. Ministério da Saúde. Desenvolvimento gerencial de unidades básicas de saúde do distrito sanitário. Projeto Gerus. Brasília: Fundação Nacional de Saúde, 1995, p. 241-244.

PEDUZZI, Marina. Equipe multiprofissional de saúde: conceito e tipologia. Revista de Saúde Pública, São Paulo, v. 35, n. 1, p. 103 109, 2001

Trabalho em equipe de saúde da perspectiva de gerentes de serviços de saúde: possibilidades da prática comunicativa orientada pelas necessidades de saúde dos usuários e da população. 2007. 247f. Tese (Livredocência) - Escola de Enfermagem. Universidade de São Paulo, São Paulo.

PIRES, Denise. Reestruturação produtiva e trabalho em saúde no Brasil. São Paulo: Annablume, 1998.

RAMMINGER, Tatiana; NARDI, Henrique Caetano. Subjetividade e trabalho: algumas contribuições conceituais de Michel Foucault. Interface - Comunicação, Saúde, Educação, Botucatu, v.12, n. 25, p. 339-346, abr./jun. 2008.

WESTPHAL, Márcia Faria; BÓGUS, Claudia Maria; FARIA, Mara de Mello. Grupos focais: experiências precursoras em programas educativos em saúde no Brasil. Boletín de la Oficina Sanitaria Panamericana, 1996, v. 120, n. 6. p. $472-81$

Recebido em 22/05/2010

Aprovado em 08/07/2010 
